\title{
Facilitators and Constraints of Policy Learning for Administrative Capacity in the Western Balkans
}

Artan Karini

\begin{abstract}
Drawing on the policy-transfer literature, where processes such as Europeanization accentuate the role of policy networks as facilitators or constraints in the implementation of acquis ${ }^{1}$, in addition to the familiar mechanism of "conditionality", the principal objective of this article is to explore the challenges of policy learning toward administrative-capacity building and, more specifically, the role of what I refer to here as "donor-bureaucrat-contractor" networks in the Western Balkans. By employing a qualitative methodology consisting of forty semi-structured interviews and focus groups with policymakers, donor officers, civil-society experts and consultants in the region during the period of January 2011 to December 2016, a critical analysis of aid-supported policy learning via training as a conduit to administrative capacity-building reveals a series of context-specific dimensions, such as the informality of such networks, overreliance on local NGOs as "capacitybuilding" implementation partners and the ability of the context to affect donor behaviour - all ultimately contributing to the (non-) occurrence of policy transfer. The overarching conclusion this article draws is that potential answers to problems with aid-supported policy learning in the region may probably lie in the invisible workings of the aforementioned networks rather than solely in the official channels of communication between Brussels and regional governments. From a policymaking standpoint, this conclusion in itself may as well be construed as a recommendation to mobilize future research surrounding the impact of such networks on European Union (EU) accession processes in the region. This may encourage research organizations both in the EU and the region to (re) orient future endeavors towards this dimension of administrative capacity-building - a core requirement for EU accession - especially as the EU itself faces its own enlargement dilemmas following Brexit while the region faces threats of a potential revival of "old" ethnic
\end{abstract}

1 EU Laws. 
conflicts, both affecting the progress of administrative reforms and prospects of EU accession.

\section{Keywords:}

policy learning, administrative capacity, networks, Western Balkans

\section{Introduction}

Capitalizing on the need for more case studies from the developing world in the policy-transfer literature and on the key objective of this article, which lies in its contribution to filling such a gap (Dolowitz and Marsh 1996, Common 1998, Stone 1999, Easterly 2003, Easterly and Pfutze 2008, Marsh and Evans 2012), the angle that I take here is to focus on a subset of actors of policy transfer, including consultants, networks and epistemic communities (Stone 2004, Evans 2009). ${ }^{2}$ Yet, while emerging research work points to the unintended consequences of aid-supported policy transfer for administrative capacity building in non-OECD country contexts (Blunt et al. 2012, Karini 2013), the evidence on the role of the "policy community" or "networks" as defined in the literature is somewhat anecdotal and continues to remain under-researched (Stone 2004, Pal 2014). The Western Balkans, which this paper focuses on, seem to be a case in point, where transfer processes are mainly analyzed - both among policy circles in Brussels and in the fairly limited research work by the regional scholars - within the scope of transfer between the EU as one supranational entity (and lead donor) to individual countries in the region as "beneficiaries" of its aid to further a specific "EU accession" policy transfer.

Drawing on the above assumptions deriving from the literature and the central research question, which is how and to what extent the process of administrative capacity has been influenced by contextual facilitators (enablers) or constraints (inhibitors), I look at the implications of what are referred to as "formal and informal" or rather "invisible" networks toward an enlarged European administrative space, Western Balkans included, not simply as agents of policy transfer but, naturally, through their role in the implementation of training programmes supported by donors. Rather than discussing the role of such networks as a development "phenomenon", the article seeks to unpack the complexities of the so-called "donor-bureaucrat-networks" - a coined collocation to substantiate the assumption that the "power" of such network is stronger than official (donor or government) reports let on. As the article more specifically contends, the "Opinion Reports" of the EC (European Commission) - representing the EU as the lead donor in the region - fail to adequately address the role of the aforementioned networks in their official accounts of policy transfer and, most relevantly, policy learning as a subset

2 The original policy transfer designed by Dolowitz and Marsh (1996) identifies "international aid organizations" and "bureaucrats" as primary actors of policy transfer. 
within it toward the given context. Such reports continue to place their emphasis on the difficult political contexts and communist legacies of the countries in the region despite the fact that December 2015 marked the $25^{\text {th }}$ anniversary of the anti-communist movements which affected the region. To re-iterate, by critically examining the interaction of donors, bureaucrats and contractors, the article is built upon a key assumption that claims that the official EU (and other donor) reports are either silent or vague about the existence of such invisible and informal networks or, at best, dismissive of their "power" in the progress of efforts towards capacity building for both EU accession processes and development in the region.

In terms of research-design and methodological considerations, the research approach employed has focused on the process (rather than outcomes) through which the "donor-bureaucrat contractor" networks - a term which will be extensively used in the analysis - might influence policy learning by bureaucrats in the research context. Therefore, rather than developing measurements which are otherwise carried out by donors via their results-based management (RBM) frameworks, the paper analyzes qualitative accounts of forty interviews with public servants, donors and civil-society representatives across the region during 2011-2016 through the elements of the original Dolowitz and Marsh (1996) conceptual framework - a toolkit guiding the research, connecting all aspects of inquiry and allowing for generalized commentary. In more practical terms, the research has built upon primary data gathered through forty semi-structured interviews and three focus groups with public-administration specialists, NGO experts and consultant in Tirana, Skopje and Prishtina during the period of January 2011 to December 2016. The transcripts of interview and focus group data were coded based on the emerging themes as the research findings unfolded. The thematic-analysis approach employed to interpret such data was supported by triangulation with secondary data sources provided by research participants and a content analysis of hard copies as well as online government and donor (mainly European Commission) reports scrutinized for the purposes of this research.

The article proceeds in five sections. The first discusses evolving debates on policy transfer, aid and development. Through an analysis of the multi-level policy transfer, the second section focuses on the application of theoretical arguments surrounding the latter to the context of the Western Balkans. The discussion of facilitators and constraints of policy transfer through the research findings occupies most of the third section. Subsequently, the fourth section discusses aspects related to donor-bureaucrat interaction and its impact on policy transfer in context. The Discussion part (section five) builds on the polemics around such interaction in policy learning, which, as will be argued, can be best understood if the gamut of policy actors is not exclusively confined to donors and bureaucrats, but rather on the role

38 of the interviews were conducted with NGO representatives, 12 with donors and the rest (20) with bureaucrats. 
of networks including NGOs and consultants in policy transfer, consistent with the original goal of the article. The Conclusions section capitalizes on this discussion and offers concrete recommendations for EU and regional policy-/decision-makers as well as for researchers.

\section{Evolving debates on the link between policy-learning aid and development}

Modern-day critics of development aid, who have researched the dynamics of aidsupported policy transfer to post-communist Central and Eastern Europe (CEE), Western Balkans being an important enclave within the region because of its aspiration to join the EU, tackle their criticism from multiple perspectives. While some blamed aid agencies for creating programmes in those countries without regard to their distinctive cultures, political and social frameworks (Miller 1998), some of them point to the importance of networks through which donors and recipients operate. Wedel $(2000,2004)$ is one of those critics. For her, aid programmes in CEE have suffered from a "gigantic disconnect between East and West forged by the Cold War and exacerbated by barriers of language, culture, distance, information and semi-closed borders" (2000, A16). In trying to explain the ethnography of aid in $\mathrm{CEE}$, she argues that "associated processes... bring to the fore the importance of networks, relationships and key brokers (such as contractors and consultants) in negotiating international aid" (Wedel 2004, 166-168; Mosse and Lewis 2005, 16).

Donor transparency and motivation in furthering policy learning or "learning from abroad" have also been subject to increasing criticism in recent years. There is literature going as far back as the 1950s that warned us of rhetorical donor selfinterests (Riddell 2007, Easterly 2010). More recent literature treating donor motivation as related to its impact on policy transfer suggests that, although both altruism and self-interest are motives for supporting it through aid, the latter is often used by governing elites and their networks to bolster political support and further economic interest (Murshed 2009, Moyo 2009, Easterly 2010). Thus, most recent research has also been able to demonstrate that aid is always linked to and often made conditional on the donors' national interests or political agenda rather than on its potential benefits for recipient countries' policy-making (Abouassi 2010). This is in convergence with the view of Browne (2006), who has argued that it is precisely because the content and terms of aid are strongly influenced by the needs and interests of suppliers rather than recipients that aid (for domestic policymaking) is still poorly matched to need.

Therefore, elements such as domestic contexts, dynamics of donor-recipient relationships and aid transparency are important factors to look at because they have clear implications for the role of aid for policy transfer in developing countries, including the context in which this research takes place. However, as in the case of 
the conventional aid theory and views associated with it, the more recent theoretical debates on aid, transfer and development still represent controversial and inconclusive views rather than well-established theories, which meaningful research should build upon. Despite the above views, there is a consensus in the literature gravitating towards a "middle ground" theoretical approach which is built upon the assumption that aid is a form of international policy transfer, which through policy learning as an important instrument, has at least the potential to impact positively on building institutional capacity (Collier 2006).

Besides, empirical research has been able to identify a correlation between the performance of bureaucracies and their capacities and the socio-economic development of less developed countries (Rodrik 2007, Holmberg and Rothstein 2009). However, on the other hand, in most cases, this has not been necessarily linked to the aid-supported policy learning provided to those countries. In this context, Collier (2006) and Booth (2011) attribute the lack of evidence of a strong positive link between aid and development outcomes to the failure of development research to take on board the centrality of "context", whose constraints limit the aid impact. Based on these arguments and in light of the criticism of aid-supported policy transfer in the Western Balkans almost exclusively occurring via policy learning of acquis communautaire as a political instrument ${ }^{4}$; this paper might indeed contribute to the debate on the link between policy transfer on the one hand and EU integration and development on the other, the latter being the original idea behind the 1999 Stability Pact for the Balkans (nowadays known as the Regional Cooperation Council) ${ }^{5}$ as well as a new focal element in 2014-2020 IPA II. ${ }^{6}$

\section{Transfer through policy learning in a Western Balkan context}

In an attempt to frame the discussion on aid and its absorption for policy toward the EU accession processes in the Western Balkans around a theoretically sound conceptual framework, I turn to the agents of the policy transfer framework, which, as both its proponents and critics argue, goes well beyond the two main groups a) international aid organizations (or "donors"), and b) bureaucrats (or public servants) (Dolowitz and Marsh 2000, Evans 2009, Benson and Jordan 2011). Despite the fact that the above two constitute the major two groups studied under the scope of this

4 The current EU candidates from the Western Balkans region are Albania, FYROM (Former Yugoslav Republic of Macedonia), Montenegro and Serbia. Croatia became an official EU member on 1 July 2013). Bosnia and Herzegovina (B\&H) and Kosovo/a are potential EU candidates.

5 The goal of the 2020 strategy of the Regional Cooperation Council for the Balkans is to improve living conditions and bring competitiveness and development back into the focus, closely following the vision of the EU strategy Europe 2020.

6 IPA II succeeds IPA (Instruments of Pre-Accession), the original mechanism created by the EU to deliver aid efficiently to the Western Balkans (2007-2013). 
research, the "policy community" (as termed in the policy-transfer literature) including other actors such as think-tanks, NGOs and international consultants can be "catalysts" of policy transfer (Stone 2004).

Hence, in the discussion that follows, the focus is on what is agreed on in both academic debates and development research and practice: the advantage of the policy-transfer framework, which lies in its ability to highlight the relationship between policy actors and the dynamics of that relationship (James and Lodge 2003). The interaction between the two identified key actors, donors and Western Balkan bureaucrats, as aid recipients in the transfer process is analyzed through training as a policy-learning modality and effective administrative capacity-building approach. Still, while regional scholars have only recently engaged in modest debates about the benefits of policy learning for the reconstruction of their post-communist societies, capacity building itself has become a vague "buzz word" to please donors but is seldom owned by beneficiaries (Pollitt and Bouckaert 2011, Karini 2013). At best, recipients of aid in the Western Balkan region have responded to donors' efforts to incorporate such concepts as part of development projects with resistance, considering it an approach for Africa but not for the region. This has pushed (EU) donors to seek alternative strategies to enhance the effectiveness of their aid by promoting collaborations and profesisonal exchanges between the region and relatively new EU member states (Poland, Hungary, etc.). ${ }^{7}$

From a theoretical perspective, the Dolowitz and Marsh (1996) multi-level approach to policy transfer and the Europeanization thesis, as a specific strand of the policy-transfer literature, both point to the salience of the administrative context in the transfer process (Evans 2009). The Europeanizaiton literature itself hightlights administrative capacity building not only as EU policy approach but also conditionality for $\mathrm{EU}$ aid, while warning that such conditionality might be insufficient for the Western Balkan region (Hoffman 2005, Petersen 2010, Karini 2016). However, this piece of research recognizes that in less mature political contexts, such as the Western Balkans, "administrative context" should not be studied merely in terms of the organizational culture and structures (Schedler and Proeller 2007, Painter and Peters 2010, Stewart 2011). Instead, building on the argument that the proof of policy transfer lies in its implementation (Evans 2009), the attention should focus on the administrative culture as reflected in the interaction between donors, bureaucrats and other actors, including consultants and "EU contractors". The facilitators and constraints of such interaction and how they affect policy-learning processes (Dolowitz and Marsh 2000, James and Lodge 2003, Benson and Jordan 2011) are part of the discussion that follows, which intends to bring to light potential variables characterizing the Western Balkan context, where public servants

7 Twinning is a European Union instrument for institutional cooperation between Public Administrations of EU Member States and beneficiary or partner countries. 
engage in aid-supported policy-learning activities, such as training, twinning and technical assistance.

\section{Facilitators and constraints of policy transfer}

Discussing the dynamics of policy transfer - be it voluntary or coercive - would be insufficient without exploring other variables, which can either facilitate or restrict the policy-transfer process. In their analysis, Dolowitz and Marsh (1996) have placed emphasis on an important factor that needs to be considered in the policytransfer process: the different political motivations of policy actors. For them, the latter often need to legitimize or justify decisions for the development of certain policies, which may be interpreted as a catalyst for why they appear to engage in transfer. In their interpretation, "it is important to understand that if policy transfer is undertaken during periods of social, political stability within a nation different actors have different motivations, then such transfer is likely to be voluntary; if there is some form of political crisis, then transfer is likely to have some coercive elements" (Dolowitz and Marsh 2000, 17). Besides, policy transfer "may also help political leaders bolster wider political support but the symbolic effect of transfer may be of greater value" (Common 1998, 72).

If we accept the above arguments, then it is necessary to account for both policy incentives behind conditions and prescriptions of aid organizations as well as the specificity and internal dynamics of the national context (political and bureaucratic culture), which may be capable of modifying transferred policies, thus determining the success of policy transfer (Common 1998, Pollitt and Bouckaert 2011). In Common's view, "for policy transfer to occur, the aspirations of the recipient country have to match those of the donor and if those (in addition to the context) are not taken into account, policy transfer becomes a major cause of policy failure" $(1998,63-71)$. Contextual factors such as "facilitators" or "constraints" of transfer have been analyzed in the literature, and other factors including path dependency, implementation, the uniqueness of the national culture were shown to be significant (Page 2000, Evans 2009; Benson and Jordan 2011).

The policy literature suggests a number of other variables, including policy complexity and feasibility, resource similarities, authoritative coercion, presence of power relations and disputes in values/interests, as well as other non-negligible factors such as language in the category of constraints/facilitators affecting the policy (transfer) process (Sabatier 1999; Dolowitz and Marsh 2000). While treating all of the above as mediating variables would be unrealistic, the discussion that follows focuses on what is agreed both in academic debates and development practice: the advantage of the policy-transfer framework, which lies in its ability to highlight the dynamics of the relationship between policy actors (James and Lodge 2003). Hence, the interaction between the two identified key actors, donors and Western Balkan 
bureaucrats, as aid recipients in the transfer process is analyzed through the macro-, meso- and micro-level approach to studying policy transfer (Dolowitz and Marsh 1996), and training is highlighted as a distinct policy-learning instrument and key variable in this work.

Overall, aid absorption with regard to the broader picture of administrativecapacity-building reform appears as a recurring theme, in a way which may constrain successful policy transfer between the EU donor(s) and Western Balkan bureaucrats. This is echoed in the account of an interview with a senior EU officer, who expressed frustration with the pace of policy-learning activities, hinting at a series of limitations to aid absorption, which have led to a mixed record of EU's technical assistance in the region. She noted:

The (Western) Balkans [policymakers] have received of lot of foreign aid. In our view, the quality of $T A^{8}$ has been generally good... However, the enhancement of administrative capacities has been rather limited... Even though we still think administrative reforms in the region is gradually happening, it requires a lot of 'pushing'...

Reflecting the ongoing issue of politicization of public administration, high staff turnover due to political changes, especially at the central level, appears to be the greatest impediment to the impact of donor-supported programmes, both in terms of general capacity-building initiatives and those tailored to administrative capacity building. It has led to a mixed record on the sustainability of training, as a specific form of policy learning and knowledge transfer from international organizations to public servants in the region.

One category in particular, specifically "mentality and attitudes", appears to be a frequently mentioned "constraint" in the transfer process, as discussed in policy-transfer theory (Dolowitz and Marsh 2000). As best put by one donor officer, changing attitudes and mentality in public institutions is one of the hardest tasks in policy learning. This is also substantiated by accounts of other actors involved in the delivery of training programmes:

[In addition to the differences between the mentality of ministries, which see aid as 'hard investments', and donors seeing it as 'investment plus policy learning'], there is limited understanding (by recipients) of the benefits of the latter for growth on individual, organizational and country levels. Additional obstacles include lack of career perspectives, responsibilities not being linked with capacities, uncertainty of positions and starting from a low base level due to poor recruitment practices in the public service.

8 Technical assistance. 
Perhaps, a 'know-it-all' attitude rather than understanding the need to upgrade skills is what undermines the impact of training. Also, the 'one-city state' mentality pervasive in the capitals of the region, where most training programmes take place while remote areas (e.g. communes) are in greater need of learning about policy, is part of the problem...

Most of the training is about EU integration rather than policies and processes in which public-administration systems operate. Besides, the lack of a culture of $M \leftrightarrow E$ (monitoring and evaluation) reflected in the bureaucrats' perceptions of it as something 'less important' rather than an effective tool to measure the impact of training is part of the problem...

(Policy) learning is not seen as a continuing process... [and] probably not understood and appreciated in the local context, [which shows in] the tendency of the bureaucrats to pay lip service' to administrative capacity building [which shows in] passive participation [in training], where trainers are not seen as facilitators but rather as 'doers'.

Indeed, recognizing the importance of "active participation" of bureaucrats as key to aiding absorption, one specific donor organization, namely the EU Delegation to X [country], has reportedly intensified its efforts to address the "participation" issue as a potential "constraint" or "facilitator" of the knowledge transfer for long-term capacity building despite challenges associated with such an approach:

The sustainability of policy learning to an extent where public servants are active in the implementation of our efforts, rather than showing passive attitudes, is increasingly a key concern for us [EU].

Besides, the extent to which aid is absorbed can be limited by other factors, including the competence of trainees and questionable practices on the part of the public organizations which nominate bureaucrats to participate in aid-supported training programmes:

Sometimes, the wrong people from ministries or other public agencies across the Western Balkan countries are sent to training or, if they are competent, they have no power in their organization they come from...

or, as a former public servant, currently employed in a donor-funded project, observes:

absorption of policy learning is also hampered by the fact that often public servants sent to the training programmes are usu- 
ally close to senior politicians or officials (but not necessarily the right ones for a given training programme) while at other times, it is not uncommon for public-service agencies to send (usually incompetent) employees to the training as a way to deal with the inflated administration...

However, as described by a senior departmental director interviewed for this research, a positive record of the role of aid in training as a key approach to capacity building and its absorption over time is undeniable:

With the time passing, because of the ongoing exposure to training (at home and abroad) as well as improvement of language skills, the public service in the Western Balkans is definitely not what it used to be in the 1990s or early 2000s or even 2010.

While the above may be interpreted as a facilitator in the knowledge-transfer process, an expert involved in several M\&E contracts for donor-funded training programmes pointed to positive changes in public servants' attitudes due to an increased interest in their own career development but only in recent years:

There are improvements in the beneficiaries' perception and absorption of the benefits of policy learning to enhance capacity ... through training in particular. Increasingly, it [training] is taken more seriously and seen [by public servants] as a complementary $H R$ resource and value-adding element in their qualifications and daily work...

A final factor, however, specifically the neglect of the national specificity and the failure to reflect contextual elements in training programmes figured as a key constraint as far as the absorption of aid towards policy learning is concerned. This resonates with the arguments discussed in both aid and policy-transfer literatures (Riddell 2007, Hyden 2008, Lavergne and Saxby 2001) and is substantiated by accounts of interviewees including those in the donor community:

The issue with some training programmes designed for public servants is that they are not contextualized with the socio-political contexts of the region. To gain ground, donors often tend to overutilize 'fashionable' terms and concepts in their programmes, which do not fit with the context; sometimes, they even go outside their core expertise...

\section{Communication between donors and bureaucrats}

The review of the literature on aid and policy transfer converged on the importance of communication between donors and recipients and the "national" context as broadly referred to in the policy-transfer framework (Rose 2005, Lancaster 2007, 
Evans 2009). Both strands of literature point to a number of specific variables that may influence such interaction, including power relations as well as institutional culture, which are not only key to effective and efficient transfer but even capable of modifying transferred policies and programmes (Common 1998, Hyden 2008, Pollitt and Bouckaert 2011). The dynamics of such interaction are reflected in policyoriented learning facilitated by different policy actors (Ladi 2005, Evans 2009).

The research results discussed below are analyzed in light of the variables discussed in the policy-transfer literature and potential ones emerging from interviews. The communication between donors and bureaucrats in the research context seems to be influenced by the manifestation of a predominantly "closed culture" typical of Western Balkan public institutions during the implementation of most capacity-building programmes. Such culture is significantly shaped by resistance to change often driven by political polarization and, specifically, a tendency to "hide problems" within the public organizations, which donors can assist with.

The arguments debated in the literature, which suggest that greater emphasis should be placed upon the technical and operational aspects of policy learning as well as the relationship between donors and recipients (Sabatier 1999, Riddell 2007) have applications for this part of the discussion as well. Thus, in the research context, the (mis)communication between donors and bureaucrats as aid recipients was exemplified either through the "lack of or poor consultation prior to" or "inappropriate timing of" the implementation of capacity-building initiatives:

While certain donors directly impose their idea of 'needs assessment' on them [bureaucrats], there are cases when training contracts are awarded to certain companies that had not consulted the beneficiary institution at all during the design phase of a proposal by the company. Besides, given that the needs assessment for a training programme happens 2-3 years before its actual start, there are times when proposed modules are no longer current or even relevant ... this does not meet our capacity building needs but deadlines of donors...

While the above may appear to represent an isolated scenario, the lack of policy convergence on administrative capacity-building needs seems to be a common concern shared by interviewees, which may be interpreted as a constraint in the donor-bureaucrat communication:

Failure to find common grounds in identifying policy learning interventions often leads to inconsistencies of TNAs ${ }^{9}$ by donors vis-à-vis those expressed by public servants consulted, which ultimately leads to failure of such initiatives...

9 Training Needs Assessment. 
Power relations, a variable broadly discussed through the policy-transfer literature (Djelic 2001; James and Lodge 2003) also seems to be a factor in the communication between donors and recipients, which in the research context can be both a "facilitator" and a "constraint". Based on the accounts of interviewees, the dynamics of power relations (in relation to certain processes, such as recruitment of consultants) can also constrain the communication with the donors. A public servant interviewed for this study exemplified this through a change in those dynamics because of the termination of the contract of an international consultant (with good technical skills but no understanding of the policy context) by his agency, affecting the relationship between the agency and the EU Delegation Office:

\begin{abstract}
Resisting the imposition of donors with regard to the choice of consultants is a very new thing ... and that became stronger with our government having a stronger voice in dealing with donors recently. A case in point is a recent decision by $Z$ [public organization] to dispense with the services of $Y$ [private contractor], recommended and contracted by the EU to perform a capacitybuilding project. In my view, this is a good thing, but I wouldn't say the situation has not caused tension between us and the EUD...
\end{abstract}

Indeed, the dynamics of power relations, especially as they relate to aid politics, internal governance of aid organizations and the presence of networks (Sabatier 1999, Wedel 2000) are increasingly important to policy transfer in developing countries. However, although the literature points to an importance of these dynamics (Celasun and Walliser 2008, Easterly 2010), one important aspect, namely the internal donor governance, is not sufficiently treated in the international policy transfer. Yet, such literature highlights the salience of the dynamics of the interaction between policy actors for policy transfer to occur (Dolowitz and Marsh 2000). In our context, the impact of the internal governance of donors, the EU included, on the donor-bureaucrat interaction appeared to be constrained by "mixed/conflicting messages" in the policy-transfer process. To illustrate the implications of this aspect for policy learning toward administrative capacity building for EU accession, a consultant interviewed for this research provided a sense of frustration with the fact that:

While the development division of $X$ [EU agency] celebrates successes working with the government initiatives to implement reform, the political division [of the same agency] issues a conflicting report, which states that 'reform in the country has hardly progressed at all...

Issues related to donor politics were reflected through the accounts of interviewees from the "policy" NGO sector, as well. In the words of a think-tank expert, clashes among donors and their agenda in the early years of transition have 
nowadays been replaced by a growing competition for "market shares" among them or even between certain donors and bigger national NGOs. While the above may be interpreted as constraints in the donor-bureaucrat interaction, other interviewees believe that certain recent changes in the internal organization of some donor agencies may have positively influenced their interaction with regional bureaucrats, contributing to more effective policy learning. A CSO expert praised the significant changes in the reporting practices within the European Commission in particular:

Once a conservative donor lacking public disclosure of reports and indicators, the EC's reporting practices are now more open. Besides, the decentralization of politics within the EC itself (with individual state members taking over its presidency regularly) has had positive implications in terms of the assessment of the impact of their capacity-building programmes because public servants now have more access to the Commission's reports.

From another perspective, a donor officer sees the accession of new member states into the $\mathrm{EU}$ as a potential facilitator in terms of the donor-recipient interaction as well as for improved EU-Western Balkan relations and more effective policy learning across public-service organizations:

The effectiveness of the EU aid towards capacity building will be enhanced when bureaucrats in the region will start to appreciate more the benefits of the expertise of their colleagues from the new member states (Poland, Hungary, etc.), whose experience is more relevant and closer to their reality.

However, as discussed earlier, the interaction between the key actors (donors and bureaucrats) is facilitated by other actors included in the policy-transfer framework, such as NGOs and consultants and contractors. Their role and specificity in the Western Balkan context (discussed below) helps to better understand the "cultural" element of the regional context.

\section{Discussion: Policy networks in the Western Balkans}

To re-iterate the earlier arguments encountered in the literature (Bennett 1991, Stone 1999, James and Lodge 2003, Dussauge-Laguna 2012), policy learning, particularly in developing, non-OECD country contexts, is facilitated by various actors, which - in addition to donors and bureaucrats - constitute the "policy community" or the "policy networks". Drawing on the salience of the policy-transfer framework, recognized for its applicability to transitional contexts and the advantage of highlighting the dynamics of relationships between policy actors (Evans 2009), accounts of interviewees have unpacked the unique complexities of these networks in imparting policy learning toward administrative capacity building in the given context. 
On the one hand, some donor officers interviewed expressed frustration with the lack of pressure groups and a strong civil society, which could otherwise perform "watchdog" roles in administrative capacity-building processes in the Western Balkans. In the absence of real "local capacity builders", NGOs are increasingly subcontracted to conduct analyses and implement training programmes through "service contracts" rather than "democratization grants", which was the case through the 1990s. On the other hand, as some interviewees echoed, those NGOs are perceived to be the most silent in the government-donor-NGO policy forums organized by aid agencies such as the OECD in recent years. On balance of findings based on the accounts of interviewees and focus-group participants, it appears that, irrespective of the acknowledgement of transfer through NGOs, their acting as "implementing partners" on behalf of donors rather than as representatives of public interests is a peculiarity of the context:

Here [in the Balkans], we are not talking about civil-society
pressure groups [but rather] NGOs, which refer to themselves
as 'centres of expertise', often using access to information and
technical knowledge [and loopholes in the legislation around the
functioning of non-profits] to access capacity-building contracts
... [Thus], rather than representing the beneficiary or even the
agenda(s) of donors contracting them, they act as private entities,
representing their very narrow private interests.

Describing NGOs as "weak and opportunistic" and hardly a reliable source for effective pressure on the governments to improve policy-making, some in the donor community realize that the main issue is that in the 1990s and early 2000s most Western Balkan NGOs came into existence either due to donor funding availability or as spun off from Western NGOs rather than inherently rising as regional civic groups. However, resembling the politicization in the public service, what seems to have undermined their core values and even damaged their image, especially most recently, is their clear political bias, i.e. siding with political parties, which limited its impact on policy learning, including training. The lack of transparency and accountability and low standards of performance in delivering capacity-building programmes are exacerbated by concerns about corrupt practices and the presence of informal "arrangements" among "capacity-building" NGOs and those who receive the training. While the establishment of formal networks (mechanisms of transfer) among donors or between donors and individual governments in the region (such as in the case of Albania) may be interpreted as a "success story" in the Balkans context, informal "donor-bureaucrat", "donor-contractor" and "bureaucrat-contractor" networks seem to prevail in the region. A first, perhaps cynical, analysis of those accounts makes references to a certain (invisible) "power" of these networks in the context, which the EU official reports are vague or silent about. 
In the views of interviewees, those networks often manifest themselves in tendencies of contractors (NGOs) to please beneficiaries in the public service and "buy their partnerships" in the implementation of capacity-building programmes. More significantly, resembling the ability of politics to alter policy transfer discussed in the literature (Common 2001, Evans 2009), the existence of such networks is also demonstrated in "clientelist" donor behaviour, whereby certain public-service structures, contractors or NGOs, foreign or local, are often favoured. As one of the interviewees put it:

certain donors are also negatively affected by the apathy and corrupt behaviours of the local environment in the region and ... in order to meet their objectives, they become easily manipulated by such an environment... There are times when a local NGO will not access a contract from a certain donor simply because it is perceived as an "ally" of another donor. At other times, even personalities of senior officials of an aid agency affect chances of how favourably (or unfavourably) a capacity-building proposal is evaluated by that agency.

The issue of "clientelism" emerged in several interviews with public servants as well. In their views, in line with earlier findings, it often demonstrates itself in the quality of donor-selected consultants, who, in some cases, have little or even nothing to do with the nature of a given capacity-building programme. Such views are challenged by individual donors like the EU, claiming their commitment to the inclusion of aid recipients as equal partners in the selection of contractors based on the rationale that when beneficiaries are involved in the selection or when local consultants are selected and employed, the implementation of capacity-building projects is more effective. Ultimately, as an interview with a senior bureaucrat revealed, donors need to reconsider their tendency to deliver training via NGOs and make more efforts to coordinate training through national public-administration reform agencies, thus strengthening their capacities as more legitimate government capacity-building entities.

\section{Conclusion}

Based on the original goals this article set out with and the key assumption that the dynamics of the interaction between the key policy actors engaged in policy transfer, donors and bureaucrats, cannot be fully understood without examining the role of networks between policy actors, including representatives of think-tanks, NGOs and consultants as "catalysts" of policy transfer, the interviews organized for purposes of this research focused on training as an instrument of policy learning. The overarching conclusion this paper draws is that the role of such networks in the Western Balkans is neglected in the official channels of communication between 
Brussels and the regional governments. Yet, the perceived limited impact of aidsupported policy learning on efforts to support the preparation of the region for "participation in the European administrative space" can be linked precisely to a certain "power" of such networks.

Through a contextual analysis of policy transfer via policy learning, this article has pointed to various constraints to policy learning through training as a capacitybuilding instrument including: a) a pre-occupation of aid-supported training programmes with topics related to EU accession and aid coordination; b) a mismatch between training-needs assessment and skills that would be required to support policy learning toward more indigenous administrative reform in the region; $c$ ) concerns about trainees with limited power in the Western Balkan public organizations they represent in donor-supported training programmes; d) problematic power relations between EU contractors and national training agencies, especially in hiring training consultants; and d) passive and conformist attitudes toward training as a potential conduit to more effective human-resources management in the Western Balkans' public-service systems and a major constraint in the absorption of EU (and international) aid towards policy learning.

From a donor governance angle, the research results revealed that often, "mixed or conflicting" feedback from donors to recipients, the existence of informal "donor-beneficiary-contractor" networks as a "coined" term I present to the readership based on the research results and the tendency of donors to over-rely on weak and opportunistic NGOs as "implementing partners" rather than "pressure groups" in the delivery of policy learning are key constraints in the particular context. Most interestingly, it can be argued that the peculiarity of the policy-learning environment in the Western Balkans lies in its capability to not only modify the policy-transfer process but perhaps even affect donor behaviour. It is hoped that such interpretations will pave future research, particularly among Western Balkan scholars interested in research going beyond EU (and bilateral donor) and official government reports in the region.

The findings of this research paper are meant to contribute to two dimensions: a) first, they obviously highlight the importance of informal networks toward policy learning as an instrument that might aid the accession of the Western Balkan countries as potential full members in the next few years; b) secondly, as the EU itself currently struggles with policy dilemmas over the migration crisis, the old threats of new "Cold War"-type tensions, global terrorism, the effects of Brexit and signs of brewing ethnic tensions in the region, this research seeks to challenge and constructively contribute to official "EU Opinion Reports" on the (unsatisfactory) progress of reforms, persistently blamed on "post-communist legacy" and "difficult political environments", which, after 25 years of changes continue to affect the region as part of the former East-European communist bloc are - in my view - still closer to being clichés rather than signalling a clear policy, or even a coherent and 
sufficient interest, of the EU in the Western Balkans. All these factors contribute to the questionable success of policy-transfer modalities the EU has launched in the last decade, including the Regional Cooperation Council (formerly known as "Stability Pact") and the most recent Berlin Process as living proof of its own potential failure in the Western Balkans, too. As this particular Southeast corner of Europe continues to struggle to negotiate the terms of its current and future relations with the EU, more research-based, rather than project-oriented policy learning would benefit the future of such relations.

From a policymaking perspective, the findings point to the need for the donors to integrate training as a form of policy learning into wider administrative capacity-building programming rather than as a stand-alone form of assistance. As such, rather than predominantly supporting accession processes, training should be needs-based, practice-oriented and include more elements of coaching as well as professional peer and South-South knowledge exchange among regional bureaucrats, who should act as facilitators rather than (passive) participants. While donors should continue the effective practice of conditioning funding of "hard investments" on improved policy learning among bureaucrats, they should also engage in more intensive policy dialogue with senior policymakers to highlight the relevance and benefits of policy learning as part of regional governments' development strategies (not necessarily confined to EU accession) rather than it (policy learning) being the domain of donors. While the continued support to civil society in the region is important, donors should not over-rely on NGOs as "capacity-building" implementers - as this would, in fact, exacerbate the dangers of the informal networks I refer to in this article - but rather engage more directly with government institutions responsible for administrative capacity building, which would be conducive to the imperative of legitimizing the state as a more effective and sustainable conduit to policy learning in the Western Balkans.

\section{References}

Abouassi, Khaldoun. 2010. "International Development Management Through a Southern Lens." Public Administration and Development 30, 116-123.

Bennett, Colin. 1991. "How States Utilize Foreign Evidence." Journal of Public Policy 33, 4.

Benson, David and Andrew Jordan. 2011. "What Have We Learned from Policy Transfer Research: Dolowitz and Marsh Revisited." Political Studies Review 9, 366-378.

Blunt, Peter; Mark Turner and Henrik Lindroth. 2012. "Patronage's Progress in PostSoeharto Indonesia." Public Administration and Development 32(1), 64-81. 
Booth, David. 2011. "Aid Effectiveness: Bringing Country Ownership (and Politics) back in." Working paper series 336, Overseas Development Institute (ODI).

Browne, Stephen. 2006. Aid and Influence: Do Donors Help or Hinder? London: EarthScan.

Celasun, Oya and Jan Walliser. 2008. "Predictability of Aid: Do Fickle Donors Undermine Aid Effectiveness?" Economic Policy (IBRD and IMF Journal Compilation), July, 545-594.

Collier, Paul. 2006. “Is Aid Oil?' An Analysis of Whether Africa Can Absorb More Aid." Journal of World Development 34(9), 1482-1497.

Common, Richard. 1998. "The New Public Management and Policy Transfer: The Role of International Organizations." In Martin Minogue, Charles Polidano and David Hulme (eds). Beyond the New Public Management: Changing Ideas and Practices in Governance. Cheltenham, UK: Edward Edgar Publishing.

Djelic, Marie-Laurie. 2001. Exporting the American Model: The Post-War Transformation of European Business. Oxford: Oxford University Press.

Dolowitz, David and David Marsh. 1996. "Who Learns What from Whom: A Review of the Policy Transfer Literature." Political Studies 44, 343-357.

Dolowitz, David and David Marsh. 2000. "Learning from Abroad: The Role of Policy Transfer in Contemporary Policy-Making." Governance: An International Journal of Policy and Administration 13(1), 5-24.

Dussauge-Laguna, Mauricio I. 2012. "On the Past and Future of Policy Transfer Research: Benson and Jordan Revisited." Political Studies Review 10(3), 313-324.

Easterly, William. 2003. The White Man's Burden: Why the West's Efforts to Aid Have Done So Much Ill and So Little Good. New York: Penguin.

Easterly William. 2010. "Making Foreign Aid Work, Religion and Ethics." Available at http://www.pbs.org/wnet/religionandethics/2010/02/19/february19-2010-making-foreign-aid-work/5718/ (last accessed in August 2012).

Easterly, William and Tobias Pfutze T. 2008. "Where does the Money Go? Best and Worst Practices in Foreign Aid." Working Paper 21, Brookings Global Economy and Development.

Evans, Mark. 2009. "Policy Transfer in Critical Perspective." Policy Studies 30(3), 243-268.

Hoffmann, Judith. 2005. "Integrating Albania: The Role of the European Union in the Democratization Process." Albanian Journal of Politics 1(1), 55-74.

Holmberg, Sören and Bo Rothstein. 2009. "Quality of Government: What You Get." Annual Review of Political Science VOL. 12: 135-161. 
Hyden, Goran. 2008. "After the Paris Declaration: Taking on the Issue of Power." Development Policy Review 26(3), 259-274.

James, Oliver and Martin Lodge. 2003. "The Limitations of Policy Transfer and Lesson Drawing for Public Policy Research." Political Studies Review 1, 179-193.

Karini, Artan. 2013. "Aid-Supported Public Service Reform and Capacity Development in Post-Communist Albania." International Journal of Public Administration (Routledge) 36(7), 469-481.

Karini, Artan. 2016. "Coordination Without Effectiveness? A Critique of the Paris Agenda in the Experience of Development Aid in Albania." European Journal of Development Research (Palgrave) 28(4), 741-757.

Ladi, Stella. 2005. Globalization, Policy Transfer and Policy Research Institutes. Cheltenham: Edward Elgar Publishing.

Lancaster, Carol. 2007. Foreign Aid: Diplomacy, Development, Domestic Politics. Chicago, IL: The University of Chicago Press.

Lavergne, Real and John Saxby. 2001. "Capacity Development: Vision and Implications. Capacity Development." Occasional Paper Series. Hull, Quebec: Policy Branch, CIDA.

Marsh, David and Mark Evans. 2012. "Policy Transfer: Into the Future, Learning from the Past." Policy Studies 33(6), 587-591.

Miller, David. 1998. "Collision and Collusion Reviews." Chronicle of Higher Education \#27, A16.

Mosse, David and David Lewis. 2005. The Aid Effect: Giving and Governing in International Development. London: Chase Publishing Services, Ltd.

Moyo, Dambisa. 2009. Why Aid Is Not Working and How There Is Another Way for Africa. New York, NY: Farrar, Strauss and Giroux.

Murshed, Syed M. 2009. "On the Non-Contractual Nature of Donor-Recipient Interaction in Development Assistance." Review of Development Economics 13(3), 416-428.

Page, Edward. 2000. Future Governance and the Literature on Policy Transfer and Lesson Drawing. ESRC Future Governance Programme paper series. London: Britannia House.

Painter, Martin and Guy B. Peters. 2010. Tradition and Public Administration. Basingstoke: Palgrave Macmillan.

Pal, Leslie. 2014. Frontiers of Governance: The OECD and Global Public Management Reform. Basingstoke: Palgrave Macmillan. 
Petersen, Anne H. 2010. "EU Conditionality - and Public Administration Reform in the Western Balkans." Available at http://rudar.ruc.dk (last accessed $20 \mathrm{Au}$ gust 2013).

Pollitt, Chris and Geert Bouckaert. 2011. Public Management Reform: A Comparative Analysis - New Public Management, Governance and the Neo-Weberian State. New York: Oxford University Press.

Riddell, Roger C. 2007. Does Foreign Aid Really Work? Oxford: Oxford University Press.

Rodrik, Dani. 2007. One Economics, Many Recipes: Globalization, Institutions and Economic Growth. Princeton: Princeton University.

Rose, Richard. 2005. Learning from Comparative Public Policy: A Practical Guide. London: Routledge.

Sabatier, Paul A. 1999. Theories of the Policy Process. $2^{\text {nd }}$ edn. Davis: University of California, Westview Press.

Schedler, Kuno and Isabella Proeller (eds). 2007. Cultural Aspects of Public Management Reform. Oxford: Oxford University Press.

Stewart, Jenny. 2011. "Tradition and Public Administration." Australian Journal of Public Administration 70, 106-108.

Stone, Diane. 1999. "Lesson Drawing and Policy Transfer." Politics 19(1), 51-59.

Stone, Diane. 2004. "Transfer Agents and Global Networks in the 'Transnationalization' of Policy." Journal of European Public Policy 11(3), 545-566.

Wedel, Janine. 2000. Collision and Collusion: The Strange Case of Western Aid to Eastern Europe. New York and Basingstoke: Palgrave Macmillan.

Wedel, Janine. 2004. "Studying through a Globalizing World: Building Method through Aidnographies." In J. Gould and H. Secher Marcussen (eds). Ethnographies of Aid: Exploring Development Texts and Encounters. International Development Studies, Occasional Paper 24. Roskilde: Roskilde University, 149-173. 